\title{
Microbiota bacteriana da conjuntiva no pré-operatório de injeção intravítrea de antiangiogêenico por degeneração macular relacionada à idade comparada com a de cirurgia de catarata
}

\author{
Preoperative conjunctival bacterial microbiota of antiangiogenic intravitreous \\ injection for age-related macular degeneration compared to cataract \\ surgery preoperative microbiota
}

\author{
José Ricardo Diniz ${ }^{1}$ \\ Kléper Carvalho Figueiredo Leitão \\ Marcos Eugênio Moraes Nunes deSouza ${ }^{3}$ \\ Maria de Fátima Alves Diniz ${ }^{4}$ \\ Judith Advincula Rocha ${ }^{5}$ \\ Marcus Augusto Gomes de Matos ${ }^{6}$ \\ Célia Maria Machado Barbosa de Castro ${ }^{7}$ \\ Carlos Teixeira Brandt ${ }^{8}$
}

Trabalho realizado na Fundação Altino Ventura - FAV Recife (PE) - Brasil.

Pós-graduando nível mestrado em Cirurgia do Centro de Ciências da Saúde da Universidade Federal de Pernambuco - UFPE - Recife (PE) - Brasil.

2 Aluno do Curso de Fellow do Departamento de Retina e Vítreo da Fundação Altino Ventura - FAV - Recife (PE) Brasil.

${ }^{3}$ Aluno do Curso de Especialização em Oftalmologia da FAV - Recife (PE) - Brasil.

${ }^{4}$ Biomédica do Laboratório de Imunopatologia Keizo Asami da UFPE - Recife (PE) - Brasil.

${ }^{5}$ Estagiária de Iniciação Científica do Laboratório de Imunopatologia Keizo Asami da UFPE - Recife (PE) Brasil.

${ }^{6}$ Mestre em Cirurgia do Centro de Ciências da Saúde da UFPE - Recife (PE) - Brasil.

Professora Adjunta do Departamento de Medicina Tropical da UFPE - Recife (PE) - Brasil.

8 Professor Titular do Departamento de Cirurgia da UFPE - Recife (PE) - Brasil.

Endereço para correspondência: José Ricardo Diniz. Fundação Altino Ventura. Rua da Soledade, 170 - Recife (PE) CEP 50070-040

E-mail: jrpdiniz@hotmail.com

Recebido para publicação em 09.06.2009

Última versão recebida em 06.05.2010

Aprovação em 14.05.2010

Nota Editorial: Depois de concluída a análise do artigo sob sigilo editorial e com a anuência da Dra. Mônica de C. Alves Paula sobre a divulgação de seu nome como revisora, agradecemos sua participação neste processo.

\begin{tabular}{l} 
RESUMO \\
\hline Objetivo: Avaliar a microbiota bacteriana da conjuntiva e perfil de \\
antibiograma no pré-operatório de injeção intravítrea de antiangiogênico \\
por degeneração macular relacionada à idade, comparando com a de \\
pacientes no pré-operatório de cirurgia de catarata. Métodos: Realizou- \\
se estudo transversal, observacional, tipo série de casos. Foram consti- \\
tuídos dois grupos: grupo I (degeneração macular) com 26 olhos de 26 \\
pacientes (12 homens/14 mulheres) com média de idades de $69,2 \pm 11,5$ \\
anos; grupo II (catarata) com 27 olhos de 27 pacientes ( 9 homens/18 \\
mulheres) com média de idades de $67,6 \pm 7,9$ anos. Os grupos foram \\
homogêneos em relação à idade (p=0,538) e ao sexo (p=0,787). Foi \\
realizada coleta de secreção do fundo de saco inferior da conjuntiva, \\
através de "swab", e imediatamente colocado em tubo contendo meio \\
líquido BHI ("brain heart infusion"). As amostras foram processadas \\
conforme técnicas laboratoriais padrão e realizado antibiograma de \\
cada colônia isolada. Resultados: Houve crescimento de 26 colônias \\
bacterianas no grupo I, com 2 olhos não apresentando crescimento e 30 \\
colônias no grupo II. Houve maior frequência de bactérias Gram posi- \\
tivas nos dois grupos: $23 / 26$ colônias ( $88,4 \%$ ) no grupo I e $29 / 30$ \\
colônias (96,7\%) no grupo II, com predomínio de Staphylococcus \\
aureus em ambos os grupos, com 16 amostras (61,5\%) e 17 (56,7\%), \\
respectivamente. Staphylococcus coagulase negativa foi a segunda bac- \\
téria mais identificada, com $19,2 \%$ no grupo I e $20,0 \%$ no grupo II. \\
Nenhuma diferença de frequência entre os grupos alcançou significância \\
estatística. Não foi observada diferença estatisticamente significante \\
nas sensibilidades das bactérias aos antibióticos testados entre os dois \\
grupos. Conclusões: Não houve diferença na distribuição das bactérias \\
e no perfil de antibiograma da microbiota conjuntival de pacientes no \\
pré-operatório de injeção intravítrea por degeneração macular, compa- \\
rada a de pacientes no pré-operatório de cirurgia de catarata. \\
Dscrios:
\end{tabular}

Descritores: Túnica conjuntiva/microbiologia; Infecções oculares bacterianas/microbiologia; Degeneração macular; Extração de catarata; Antibioticoprofilaxia; Injeções; Inibidores de angiogênese/administração \& dosagem 
220 Microbiota bacteriana da conjuntiva no pré-operatório de injeção intravitrea de antiangiogênico por degeneração macular relacionada à idade comparada com a de cirurgia de catarata

\section{INTRODUÇÃOO}

A endoftalmite infecciosa pós-operatória, embora rara, é uma das mais graves complicações da cirurgia intraocular, com pobre prognóstico visual. Apresenta incidência variável de 0,07 a $0,265 \%$ em cirurgias de catarata ${ }^{(1-2)}$.

Acredita-se que, na maior parte dos casos, a fonte do agente infeccioso seja bactérias da própria microbiota conjuntival (MC) dos pacientes operados ${ }^{(3-6)}$. Este fato é bem comprovado em relação à cirurgia de catarata e sugere-se que uma vez se reduzindo ou eliminando as colônias bacterianas na superfície ocular, poderia haver uma diminuição da incidência de endoftalmite pós-operatória. Uso de iodopovidona e antibióticos tópicos no pré-operatório são medidas utilizadas com este objetivo $^{(7)}$.

Injeções intravítreas de antiangiogênicos têm se tornado terapia padrão para degeneração macular relacionada à idade (DMRI), uma das principais causas de cegueira legal em idosos no mundo ocidental ${ }^{(8-11)}$. Na sua forma exsudativa, drogas como ranibizumab e bevacizumab têm revolucionado o tratamento nos últimos anos, aumentando exponencialmente o número de injeções intravítreas ${ }^{(10-11)}$.

Com o aumento das injeções intravítreas para DMRI, cresce também a preocupação com as complicações associadas. Existe um risco inerente ao procedimento de endoftalmite infecciosa ${ }^{(8)}$. Endoftalmite pós-injeção intravítrea tem um incidência muito variável na literatura, com índices desde $0,02 \%$ por procedimento até $2,0 \%$ por olho em algumas casuísticas. Isto acontece porque o tratamento é feito de forma periódica com injeções intravítreas mensais e, em alguns casos, faz-se repetição do procedimento por até 24 meses consecutivos, elevando o risco de endoftalmite ao longo do tempo ${ }^{(10)}$.

A profilaxia de endoftalmite pós-injeção intravítrea em DMRI é baseada nos estudos direcionados para cirurgia de catarata. A escolha do antibiótico tópico profilático é feita por extrapolação dos achados da MC na cirurgia de catara$\mathrm{ta}^{(12)}$. Não existem pesquisas abordando diretamente $\mathrm{MC}$ em portadores de DMRI exsudativa.

Some-se a isso o fato que a DMRI ainda não tem sua fisiopatologia totalmente esclarecida. Acredita-se atualmente numa modificação genética que leva à ativação anormal do sistema complemento que, em última análise, gera uma resposta inflamatória no tecido sub-retiniano. As drusas e lesões nas células do epitélio pigmentar da retina (EPR) seriam consequência desta inflamação local ${ }^{(13)}$.

Se a DMRI tem componente inflamatório na sua fisiopatologia, esta alteração poderia, em tese, estar presente em outros locais do organismo, levando, por exemplo, a modificações no microambiente da conjuntiva e consequente alteração da microbiota local.

O objetivo do presente estudo foi então de avaliar a microbiota bacteriana da conjuntiva e perfil de antibiograma no pré-operatório de injeção intravítrea de antiangiogênico por DMRI, comparando com a microbiota de pacientes no préoperatório de cirurgia de catarata.

\section{MÉTODOS}

Realizou-se estudo transversal, observacional, tipo série de casos, em pacientes atendidos na Fundação Altino Ventura, Recife - Pernambuco, sendo constituídos dois grupos:

- Grupo I (DMRI): 26 olhos/26 pacientes com indicação de tratamento por injeção intravítrea de antiangiogênico para DMRI exsudativa, segundo critérios pré-definidos de atividade da doença ${ }^{(14)}$.

- Grupo II (catarata): 27 olhos/27 pacientes em pré-operatório de cirurgia de catarata, sem sinais de DRMI à fundoscopia, isto é, drusas, atrofia do EPR ou membrana nevascular sub-retiniana (MNVSR).

Foram considerados critérios de exclusão para ambos os grupos:

- Uso de antibiótico tópico ou sistêmico e/ou cirurgia ocular nos últimos seis meses;

- Tratamento prévio para DMRI por terapia fotodinâmica com verterporfirina ou terapia com antiangiogênico (bevacizumab, ranibizumab ou pegaptanib);

- Sinais de infecção ocular ou sistêmica ativa;

- Usuários de lentes de contato;

- Diabetes mellitus;

- Usuários de colírio hipotensor para glaucoma;

- Presença de catarata com opacificação que impedisse exame adequado de fundoscopia.

Todos pacientes foram submetidos a exame oftalmológico completo e os pacientes do grupo I foram submetidos também à retinografia e angiografia fluorescente (Retinógrafo TRC-50 IA, Topcon ${ }^{\circledR}$ ) e tomografia de coerência óptica (Stratus $\mathrm{OCT}^{\mathrm{TM}}$, Carl Zeiss Meditec, Inc), para confirmação do tipo de MNVSR e indicação de tratamento com antiangiogênico.

A coleta do material foi realizada no período de novembro de 2008 a novembro de 2009 , no pré-operatório imediato, na sala de espera anexa ao bloco cirúrgico e sem administração de qualquer colírio prévio. Utilizou-se um "swab" para se coletar o conteúdo do fundo de saco conjuntival inferior, com movimento de rotação e deslizamento sobre a superfície da conjuntiva palpebral e fundo de saco conjuntival inferiores, sem tocar nas margens palpebrais e cílios. Este procedimento foi realizado por um dos dois autores (JRD ou MENMS), utilizando-se da mesma técnica de coleta, previamente treinada e revisada.

Os "swabs" foram colocados imediatamente num tubo de ensaio contendo dois mililitros de meio de cultura líquido "brain heart infusion" (BHI) e enviados para o laboratório em no máximo duas horas após coleta. Todo o material microbiológico ficou imerso no meio de cultura e o tubo permaneceu hermeticamente fechado até análise laboratorial.

No Laboratório de Imunopatologia Keiso Asami (LIKA), o material foi incubado em estufa bacteriológica a $36^{\circ} \mathrm{C} \pm$ $1^{\circ} \mathrm{C}$ por até cinco dias. Os tubos foram observados a cada 24 horas para verificar o crescimento de bactérias pela turva- 
ção do meio. O material dos tubos que apresentaram turvação foi semeado em meio Ágar Sangue hemácias de carneiro a 5\% e Ágar Levine para isolamento e identificação das bactérias, conforme técnicas laboratoriais padrão ${ }^{(15)}$. Caso não houvesse crescimento bacteriano no período de cinco dias, as culturas foram consideradas negativas.

Para as culturas positivas, foi realizado antibiograma através da técnica de difusão em disco. A leitura foi feita medindo-se o diâmetro do halo de inibição ao redor do disco de acordo com critérios do "Clinical and Laboratorial Standards Institute" (CLSI) ${ }^{(16)}$. Os seguintes antibióticos foram testados: tobramicina, gentamicina, cefalotina, cloranfenicol, vancomicina, neomicina, ciprofloxacino, moxifloxacino, oxacilina, ofloxacino e cefotaxima.

Para análise estatística, foram utilizados o teste Qui-quadrado de Pearson e o teste Exato de Fisher para as variáveis qualitativas e o teste $t$ de Student, para as variáveis quantitativas. Utilizou-se o programa "Statistical Package for the Social Sciences $^{\circledR}{ }^{\circledR}$, versão 13 e foi aceito $p<0,05$ para rejeição da hipótese de nulidade.

A pesquisa foi iniciada após aprovação pelo Comitê de Ética da Fundação Altino Ventura e todos pacientes assinaram consentimento livre e esclarecido.

\section{RESULTADOS}

O grupo I (DMRI) foi composto por 14 pacientes do sexo feminino e 12 do sexo masculino, com média de idade de $69,2 \pm 11,5$ anos; o grupo II (catarata) apresentava 18 pacientes do sexo feminino e 9 do masculino, com média de idade de 67,6 \pm 7,9 anos. Os dois grupos foram homogêneos na comparação da média de idade $(\mathrm{p}=0,538)$ e também em relação ao sexo $(p=0,787)$, apesar de maior predomínio de mulheres no grupo II $(56,2 \%)$.

Houve positividade da cultura de secreção conjuntival em 24 das 26 amostras (92,3\%) do grupo I (DMRI) e em todas as 27 amostras $(100,0 \%)$ do grupo II (catarata). No grupo I, houve crescimento de uma espécie bacteriana por amostra em 23 olhos $(95,8 \%)$, sendo que em um desses casos foram identificadas cepas diferentes de Staphylococcus aureus, inclusive com antibiogramas diferentes. Em outro olho $(4,1 \%)$, houve crescimento de duas espécies bacterianas. Já no grupo II, foram identificadas duas bactérias por olho em 3 casos (10,0\%), enquanto nos demais olhos uma bactéria por olho $(90,0 \%)$.

Houve maior frequência de bactérias Gram positivas nos dois grupos: 23 colônias dentre $26(88,4 \%)$ no grupo I e 29 dentre 30 colônias $(96,7 \%)$ no grupo II. Não houve diferença entre as frequências dos dois grupos. $\mathrm{p}=0,327$ (Gráfico 1).

Staphylococcus aureus e Staphylococcus coagulase negativa (StaCon) foram as bactérias mais frequentemente isoladas nas culturas de ambos os grupos. No grupo I, foram isoladas 16 colônias $(61,5 \%)$ de $S$. aureus e $5(19,2 \%)$ de StaCon. No grupo II, foram 17 (56,7\%) colônias de S. aureus e $6(20,0 \%)$ de StaCon. Não houve diferença estatisticamente

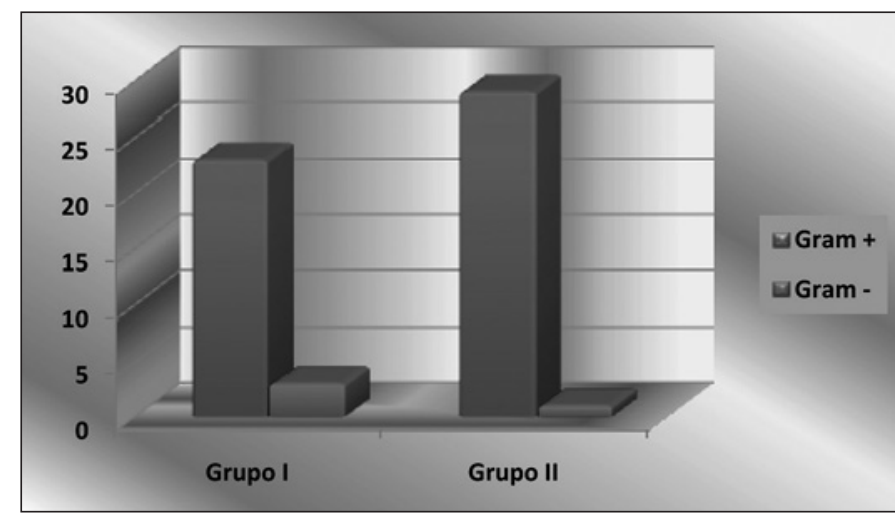

Gráfico 1 - Distribuição das bactérias cultivadas dos sacos conjuntivais dos olhos do grupo I (DMRI) e do grupo II (catarata) segundo coloração de Gram

significante nas frequências destas duas bactérias entre os dois grupos, com $\mathrm{p}=0,662$ e 0,763 , respectivamente. Outras bactérias foram isoladas com menores frequências, como bactérias Gram negativas: Morganella morganii, Citrobacter sp. e Klebsiella pneumoniae em um olho cada $(3,8 \%)$ no grupo I e Morganella morganii em um caso (3,3\%), no grupo II (Tabela 1).

Dos vários antibióticos testados, todas as bactérias de ambos os grupos apresentaram 100,0\% de sensibilidade ao moxifloxacino e ofloxacino. Quando comparadas as respostas entre os dois grupos, não houve diferença estatisticamente significante. Houve menores taxas de sensibilidade das bactérias do grupo I (DMRI) comparadas com as do grupo II (catarata) para os antibióticos tobramicina $(76,9 / 90,0 \%)$ e oxacilina $(80,8 / 93,3 \%)$. Estas diferenças, porém, não se mostraram significantes, $p=0,277$ e $p=0,231$, respectivamente (Tabela 2).

\section{DISCUSS ÃO}

Estudar os possíveis fatores que interferem na constituição da $\mathrm{MC}$ e ainda a resposta das bactérias aos diferentes antibióticos é de suma importância para escolha de profilaxia antibiótica e também tratamento de endoftalmite. Especulouse, neste estudo, que a DMRI exsudativa com sua fisiopatologia inflamatória poderia ser um destes fatores modificadores da MC.

Sabe-se que algumas condições podem levar a alterações na MC. Houve preocupação dos pesquisadores de se ampliar os critérios de exclusão na tentativa de se eliminar possíveis variáveis de confusão que também pudessem interferir nos resultados encontrados. Assim, diabetes, infecção ocular ou sistêmica, uso de antibióticos ou cirurgia ocular nos últimos seis meses e glaucoma foram considerados critérios de exclusão ${ }^{(17-19)}$.

A idade reconhecidamente é um fator modificador independente da MC. Desde o nascimento, a partir da transferência de bactérias no canal do parto até idades mais avançadas onde ocorre aumento da positividade das culturas, há varia- 
222 Microbiota bacteriana da conjuntiva no pré-operatório de injeção intravitrea de antiangiogênico por degeneração macular relacionada à idade comparada com a de cirurgia de catarata

\begin{tabular}{|c|c|c|c|c|c|}
\hline \multirow{3}{*}{ Bactérias isoladas } & \multicolumn{4}{|c|}{ Grupos } & \multirow{3}{*}{ p } \\
\hline & \multicolumn{2}{|c|}{ I (26 olhos) } & \multicolumn{2}{|c|}{ II (27 olhos) } & \\
\hline & $\mathbf{n}$ & $\%$ & $n$ & $\%$ & \\
\hline Staphylococcus aureus & 16 & 61,5 & 17 & 56,7 & $0,662^{(1)}$ \\
\hline Staphylococcus coagulase negativa & 5 & 19,2 & 6 & 20,0 & $0,763^{(2)}$ \\
\hline Morganella morganii & 1 & 3,8 & 1 & 3,3 & \\
\hline Citrobacter sp. & 1 & 3,8 & 0 & 0,0 & \\
\hline Klebsiella pneumoniae & 1 & 3,8 & 0 & 0,0 & \\
\hline Streptococcus grupo D & 1 & 3,8 & 1 & 3,3 & \\
\hline Staphylococcus saprophyticus & 1 & 3,8 & 1 & 3,3 & \\
\hline Streptococcus viridans & 0 & 0,0 & 1 & 3,3 & \\
\hline Bacillus sp. & 0 & 0,0 & 3 & 10,0 & \\
\hline Total & 26 & 100,0 & 30 & 100,0 & \\
\hline
\end{tabular}

Tabela 2. Padrão de sensibilidade das colônias bacterianas isoladas do saco conjuntival dos pacientes do grupo I (DMRI) e grupo II (catarata) segundo antibióticos testados

\begin{tabular}{|c|c|c|c|c|c|}
\hline \multirow{3}{*}{ Antimicrobianos } & \multicolumn{4}{|c|}{ Grupos } & \multirow{3}{*}{$\mathbf{p}^{(1)}$} \\
\hline & \multicolumn{2}{|c|}{ I $(n=26)$} & \multicolumn{2}{|c|}{ II $(n=30)$} & \\
\hline & n & $\%$ & $\mathbf{n}$ & $\%$ & \\
\hline Tobramicina $(10 \mu \mathrm{g})$ & 20 & 76,9 & 27 & 90,0 & 0,277 \\
\hline Gentamicina $(10 \mu \mathrm{g})$ & 23 & 88,5 & 28 & 93,3 & 0,654 \\
\hline Cefalotina $(30 \mu \mathrm{g})$ & 24 & 92,3 & 29 & 96,7 & 0,592 \\
\hline Cloranfenicol $(30 \mu \mathrm{g})$ & 26 & 100,0 & 27 & 90,0 & 0,240 \\
\hline Vancomicina $(30 \mu \mathrm{g})$ & 25 & 96,2 & 29 & 96,7 & 1,000 \\
\hline Neomicina $(30 \mu \mathrm{g})$ & 24 & 92,3 & 27 & 90,0 & 1,000 \\
\hline Ciprofloxacino $(5 \mu \mathrm{g})$ & 24 & 92,3 & 29 & 96,7 & 0,592 \\
\hline Moxifloxacino $(5 \mu \mathrm{g})$ & 26 & 100,0 & 30 & 100,0 & ** \\
\hline Oxacilina $(1 \mu \mathrm{g})$ & 21 & 80,8 & 28 & 93,3 & 0,231 \\
\hline Ofloxacino $(5 \mu \mathrm{g})$ & 26 & 100,0 & 30 & 100,0 & ** \\
\hline Cefotaxima $(30 \mu \mathrm{g})$ & 25 & 96,2 & 30 & 100,0 & 0,464 \\
\hline \multicolumn{6}{|c|}{$\begin{array}{l}\text { Gl=grupo } \text {; Gll=grupo II; } n=\text { número de colônias bacterianas testadas; } \mathrm{S}=\text { número } \\
\text { de colônias sensíveis; } \%=\text { frequência relativa em porcentual } \\
\left({ }^{\star \star}\right)=\text { não foi possível determinar devido à ausência de uma das categorias; } \\
{ }_{(1)}=\text { através do teste Exato de Fisher }\end{array}$} \\
\hline
\end{tabular}

ções nos constituintes da $\mathrm{MC}^{(20)}$. Os grupos do estudo tiveram médias de idade semelhantes. Não houve, portanto, influência do fator idade na distribuição de bactérias da $\mathrm{MC}$ nesta avaliação.

Em relação aos tipos bacterianos encontrados, houve predomínio de bactérias Gram positivas em ambos os grupos, dado concordante com a literatura pesquisada ${ }^{(18-22)}$. Não houve, porém, diferença estatisticamente significante na proporção dessas bactérias entre os dois grupos. Ressalta-se que essas bactérias também são as mais frequentes em casos de endoftalmite pós-facectomia ${ }^{(23)}$, corroborando com a origem delas a partir da MC.

Das bactérias Gram positivas isoladas, duas destacaramse: Staphylococcus aureus e Staphylococcus coagulase negativa, que são, em geral, as bactérias mais frequentes da $\mathrm{MC}^{(18-22)}$. Na comparação entre os dois grupos, porém, não houve diferença significante na frequência relativa de cada bactéria isoladamente.

É interessante observar que usualmente o StaCon é a bactéria mais frequentemente isolada de culturas de conjuntiva sadia, com porcentuais de 52 a $79 \%{ }^{(18-22)}$. No presente estudo, o $S$. aureus foi mais frequente, com porcentuais de 56 a $61 \%$ do total. Ficou então a pergunta dos motivos da maior frequência de $S$. aureus nos pacientes estudados, contrariando boa parte da literatura, que mostra frequências menores variando de 5 a $12 \%^{(18-22)}$, incluindo um estudo de 2005 na mesma Instituição que mostrou predominância de StaCon em torno de $71 \%$ dos $\operatorname{casos}^{(18)}$.

$\mathrm{Na}$ realidade, o desenho do estudo não permite responder esta pergunta, e sim se a MC dos grupos avaliados eram iguais ou diversas. Porém, algumas considerações podem ser feitas.

Primeiro, existe grande variação de metodologia empregada nos diversos estudos, que termina influenciando a distribuição das bactérias da $\mathrm{MC}^{(22)}$. Séries mais antigas, por exemplo, mostram maiores frequências de $S$. aureus, superando o $\mathrm{StaCon}^{(24)}$. O método empregado no presente estudo não permitiu a avaliação de bactérias anaeróbias estritas. Isto se deveu ao fato desta técnica apresentar alto custo financeiro e requerer condições especiais para sua realização. Propionibacterium acnes, por exemplo, encontrado em até 33\% dos casos numa casuística com bactérias anaeróbias estritas ${ }^{(19)}$, deixou de ser avaliado nesta pesquisa.

Por outro lado, o tamanho reduzido da amostra também pode ter contribuído para representação menos consistente da distribuição das bactérias da MC. Houve dificuldade de se aumentar a amostra, especialmente nos casos do grupo I de DMRI exsudativa ativa, já que se trata de um subtipo específico de menos frequência da doença. Além disso, houve necessidade da observação de muitos critérios de exclusão, fato que dificultou até mesmo a formação do grupo de portadores de catarata, doença mais frequente que a DMRI.

Existem poucos artigos na literatura nacional mostrando os tipos de bactérias associadas à endoftalmite pós-cirúrgica. 
Dois levantamentos, ambos em São Paulo, no período de 1985 a $93^{(25)}$ e de 1993 a $98^{(26)}$, revelaram o $S$. aureus como bactéria mais frequente causadora de endoftalmite. Neles foram incluídos casos de endoftalmite de outras etiologias, como póstrauma, úlcera de córnea e transplante de córnea. Mas, mesmo quando se isolou os casos pós-cirurgia de catarata, o $S$. aureus permaneceu bem mais frequente, com $63,3 \%$ no período até $1993^{(25)}$. Estes dados são discordantes da literatura internacional, que aponta o StaCon como bactéria mais frequente ${ }^{(23)}$.

Como as bactérias que causam endoftalmite têm origem na $\mathrm{MC}^{(3-6)}$, o achado do presente estudo sugere um possível maior papel do $S$. aureus como agente bacteriano causador de endoftalmite em nosso meio. Entretanto, não existem levantamentos recentes de etiologia da endoftalmite na Instituição do estudo, o que poderia de fato contribuir para validar este achado.

Em relação aos antibióticos testados, observou-se boa resposta das bactérias isoladas em ambos os grupos. Não foi observada diferença estatisticamente significante no padrão de resposta a cada antibiótico entre os dois grupos. Vale ressaltar os antibióticos tobramicina e oxacilina, onde se observou diferença de sensibilidade das bactérias de até 13,1\% entre os dois grupos, contudo sem esta ter significância estatística $(\mathrm{p}=0,277)$.

Os resultados obtidos não mostraram diferenças significantes entre a MC de portadores de DMRI exsudativa e de catarata. Esta observação tem seu valor por permitir que se aplique o mesmo raciocínio de utilização de antibióticos para eliminação de bactérias da MC no pré-operatório de cirurgia de catarata para pacientes que serão submetidos à injeção intravítrea de antiangiogênico por DMRI.

O tema endoftalmite e sua relação com as bactérias da MC desperta interesse em toda comunidade oftalmológica. Isto vale especialmente no caso de injeção intravítrea por DMRI, onde há reduzido conhecimento na literatura sobre o tema. Propõe-se aumentar a amostra de ambos os grupos, além de estudar a longo prazo os efeitos da profilaxia antibiótica tópica sobre a MC em múltiplas injeções intravítreas, linha de pesquisa esta em andamento.

Vale ressaltar também o valor do exame cultura de secreção conjuntival. Este exame, que já foi considerado rotina no pré-operatório, foi abandonado da propedêutica pré-operatória pela melhoria da técnica cirúrgica e diminuição da incidência de endoftalmite nos últimos 20 anos. As diferenças no perfil da MC encontradas nestes pacientes quando comparadas aos dados da literatura reforçam a necessidade de se realizar avaliações periódicas pela cultura de secreção conjuntival, já que orientam possíveis mudanças de profilaxia e tratamento de complicações infecciosas.

\section{CONCLUSÕES}

Não houve diferença na distribuição das bactérias e no perfil de antibiograma da microbiota conjuntival de pacien- tes no pré-operatório de injeção intravítrea por DMRI, comparada a de pacientes no pré-operatório de cirurgia de catarata.

\section{ABSTRACT}

Purpose: To evaluate the conjunctival bacterial microbiota and antibiogram profile in the preoperative of antiangiogenic intravitreous injection for age-related macular degeneration, and compare to the preoperative microbiota of patients submitted to cataract surgery. Methods: Cross-sectional, observational, case series study. Two groups were organized: group I (macular degeneration) with 26 eyes from 26 patients ( $12 \mathrm{men} / 14$ women) with mean age of $69.2 \pm 11.5$ years; group II (cataract) with 27 eyes from 27 patients $(9$ men/18 women) with mean age of $67.6 \pm 7.9$ years. The groups were similar regarding age $(p=0.538)$ and gender $(p=0.787)$. The lower conjunctival sac was swabbed and the obtained material was immediately put in a tube filled with liquid culture media BHI ("brain heart infusion"). Samples were processed according to standard laboratory techniques and antibiogram was determined for each bacterial colony. Results: Twentysix bacterial colonies growth in group I, with 2 eyes showing no growth and 30 colonies growth in group II. Gram positive bacteria were more prevalent in both groups: $23 / 26$ colonies (88.4\%) in group I and 29/30 colonies (96.7\%) in group II, with a Staphylococcus aureus predominance in both groups, with 16 samples (61.5\%) and $17(56.7 \%)$, respectively. Coagulase negative Staphylococcus was the second most common identified bacteria, with $19.2 \%$ in group I and $20.0 \%$ in group II. No differences between the groups reached statistical significance. No statistically significant difference was noted on the antibiotic sensibility between both groups. Conclusions: There was no difference in the distribution of bacteria and antibiogram profile of the conjunctival microbiota in the preoperative of intravitreous injection of antiangiogenic for macular degeneration compared to the preoperative of cataract surgery.

Keywords: Conjunctiva/microbiology; Eye infections, bacterial/microbiology; Macular degeneration; Cataract extraction; Antibiotic prophylaxis; Injections; Angiogenesis inhibitors/administration \& dosage

\section{REFERÊNCIAS}

1. Lemley CA, Han DP. Endophthalmitis: a review of current evaluation and management. Retina. 2007;27(6):662-80. Erratum in: Retina. 2007;27(7): table of contents. Dosage error in article text. Comment in: Retina. 2008;28(2):367-8; author reply 368 .

2. Moshirfar M, Feiz V, Vitale AT, Wegelin JA, Basavanthappa S, Wolsey DH Endophthalmitis after uncomplicated cataract surgery with the use of fourth-generation fluoroquinolones: a retrospective observational case series. Ophthalmology 2007;114(4):686-91. Comment in: Ophthalmology. 2008;115(2):413-4; author reply 414

3. Speaker MG, Milch FA, Shah MK, Eisner W, Kreiswirth BN. Role of external 
224 Microbiota bacteriana da conjuntiva no pré-operatório de injeção intravitrea de antiangiogênico por degeneração macular relacionada à idade comparada com a de cirurgia de catarata

bacterial microbiota in the pathogenesis of acute postoperative endophthalmitis Ophthalmology. 1991;98(5):639-49.

4. Leong JK, Shah R, McCluskey PJ, Benn RA, Taylor RF. Bacterial contamination of the anterior chamber during phacoemulsification cataract surgery. Cataract Refract Surg. 2002;28(5):826-33. Comment in: J Cataract Refract Surg. 2003;29(8):1465-6; author reply 1446. J Cataract Refract Surg. 2002; 28(5):729-30. J Cataract Refract Surg. 2003;29(1):7; author reply 7.

5. Bannerman TL, Rhoden DL, McAllister SK, Miller JM, Wilson LA. The source of coagulase-negative staphylococci in the Endophthalmitis Vitrectomy Study. A comparison of eyelid and intraocular isolates using pulsed-field gel electrophoresis. Arch Ophthalmol. 1997;115(3):357-61.

6. De Caro JJ, Ta CN, Ho HK, Cabael L, Hu N, Sanislo SR, et al Bacteria contamination of ocular surface and needles in patients undergoing intravitreal injections. Retina. 2008;28(6):877-83

7. Ciulla TA, Starr MB, Masket S. Bacterial endophthalmitis prophylaxis for cataract surgery: an evidenced based update. Ophthalmology. 2002;109(1):13-24

8. Jager RD, Aiello LP, Patel SC, Cunningham ET Jr. Risks of intravitreous injection: a comprehensive review. Retina. 2004;24(5):676-98.

9. Resnikoff S, Pascolini D, Etya'ale D, Kocur I, Pararajasegaram R, Pokharel GP, et al. Global data on visual impairment in the year 2002. Bull World Health Organ. 2004;82(11):844-51.

10. Rosenfeld PJ, Brown DM, Heier JS, Boyer DS, Kaiser PK, Chung CY, Kim RY; MARINA Study Group. Ranibizumab for neovascular age-related macula degeneration. N Engl J Med. 2006;355(14):1419-31. Comment in:N Engl J Med. 2006;355(14):1409-12. N Engl J Med. 2007;356(7):748-9; author reply 749-50 N Engl J Med. 2007;356(7):747-8; author reply 749-50. N Engl J Med. 2006 355(14):1493-5.

11. Avery RL, Pieramici DJ, Rabena MD, Castellarin AA, Nasir MA, Giust MJ Intravitreal bevacizumab (avastin) for neovascular age-related macular degeneration. Ophthalmology. 2006;113(3):363-72. Comment in: Ophthalmology. 2007; 114(2):400; author reply 400-1.

12. Ta CN. Minimizing the risks of endophthalmitis following intravitreous injections. Retina. 2004;24(5):699-705.

13. Gehrs KM, Anderson DH, Johnson LV, Hageman GS. Age-related macular degeneration - emerging pathogenetic and therapeutic concepts. Ann Med. 2006;38(7):450-71
14. Regillo CD, Brown DM, Abraham P, Yue H, Ianchulev T, Schneider S, et al. Randomized, double-masked, sham-controlled trial of ranibizumab for neovascular age-related macular degeneration: PIER Study year 1. Am J Ophthalmol. 2008;145(2):239-48

15. Brinser J, Burd E. Principles of diagnostic ocular microbiology. In: Tabbara KF, Hyndiuk RA, editors. Infection of the eye. Boston: Little, Brown; 1996. p.69-84.

16. Wikler MA, Hindler JF, Cockerill FR, Patel JB, Bush K, Powell M, et al. Performance standards for antimicrobial disk susceptibility tests; approved standard. $10^{\text {th }}$ ed. Pennsylvania: Clinical and Laboratory Standards Institute; 2009.

17. Bilen H, Ates O, Astam N, Uslu H, Akcay G, Baykal O. Conjunctival microbiota in patients with type 1 or type 2 diabetes mellitus. Adv Ther. 2007; 24(5): 1028-35.

18. Arantes TEF, de Castro CMMB, Cavalcanti RF, Severo MS, Diniz MFA, Urtiga RWD. Microbiota bacteriana conjuntival após uso tópico de ciprofloxacino e gatifloxacino em cirurgia de catarata. Arq Bras Oftalmol. 2008;71(2): 191-6.

19. De Kaspar HM, Kreidl KO, Singh K, Ta CN. Comparison of preoperative conjunctival bacterial microbiota in patients undergoing glaucoma or cataract surgery. J Glaucoma. 2004;13(6):507-9.

20. Rubio EF. Influence of age on conjunctival bacteria of patients undergoing cataract surgery. Eye (Lond). 2006;20(4):447-54

21. Locatelli CI, Kwitko S, Simonetti AB. Conjunctival endogenous microbiota in patients submitted to cataract surgery. Braz J Microbiol. 2003;34(3):203-9.

22. Rubio EF. [Conjunctival bacterial of patients undergoind cataract surgery: changes in the last 50 years]. Arch Soc Esp Oftalmol. 2004;79(1):13-9. Spanish.

23. Han DP, Wisniewski SR, Wilson LA, Barza M, Vine AK, Doft BH, et al. Spectrum and susceptibilities of microbiologic isolates in the Endophthalmitis Vitrectomy Study. Am J Ophthalmol. 1996;122(1):1-17. Erratum in: Am J Ophthalmol. $1886 ; 122(6) ; 920$

24. Osato MS. Normal ocular microbiota. In: Pepose JS, Holland GN, Wilhelmus KR, editors. Ocular infection and immunity. St. Louis: Mosby; 1996. p.191-9.

25. Chaib AR, de Freitas D, Scarpi MJ, Guidugli T. Pesquisa laboratorial em endoftalmite. Arq Bras Oftalmol. 1997;60(3):250-7.

26. Schirmbek T, Romão E, Rodrigues MLV, Figueiredo JFC. Endoftalmite: uma análise de 58 casos. Arq Bras Oftalmol. 2000;63(1):34-44.

\section{Jos artigos enviados para publipapão, o nome dos} autores \& suas afjJacões ifovem estar completos. Isso factilitara a jndexarajo o os ljuls com as bases do dadios o o EV Latios. 